\title{
LA SUPERIORIDAD \\ DE LOS ECONOMISTAS
}

\author{
Marion Fourcade* \\ Etienne Ollion** \\ Yann Algan***
}

W n las ciencias sociales hay un orden jerárquico implícito que a sí mismos en la cúspide o cerca de la cúspide de la jerarquía de las disciplinas. En una encuesta realizada en la década de 2000, Colander (2005) encontró que el $77 \%$ de los estudiantes de posgrado de Economía en los programas de élite estaban de acuerdo en que "la economía es la más científica de las ciencias sociales”. Hace unos 15 años, Richard Freeman $(1999,141)$ especuló sobre los orígenes de tal convicción. Su valoración era simple: "Los científicos sociales y los politólogos tienen herramientas analíticas menos poderosas y saben menos que nosotros, o eso creemos. Según la puntuación en el GRE y otros criterios, nuestra disciplina atrae estudiantes más fuertes que los suyos, y nuestros cursos son matemáticamente más exigentes".

* Profesora de sociología en la Universidad de California, Berkeley, CA, e investigadora asociada del Max Planck Sciences Po Center, París, [fourcade@ berkeley.edu].

** Investigador del Centre National de la Recherche Scientifique, Universidad de Estrasburgo, [ollion@unistra.fr].

*** Profesor de economía en Sciences Po, París, [yann.algan@sciencespo.fr]. Agradecemos a Johannes Buggle, Alizée Delpierre, Fatine Guedira, Daniel Kluttz, y Maxime Sauzet por su ayuda en la investigación. Estamos muy agradecidos con David Autor, Julien Boelaert, Claude Fischer, Eric Giannella, Arthur Goldhammer, Peter Gourevitch, Pierre-Olivier Gourinchas, Johan Heilbron, Chang-Tai Hsieh, Daniel Kluttz, Ulrike Malmendier, Philippe Martin, Victor Nee, Gérard Roland, Heddy Riss, Timothy Taylor y los participantes en el seminario CCOP de la Universidad de California en Berkeley por sus útiles comentarios. Este escrito se difundió como artículo de discusión del Max Planck Science Po Center y se publicó en Journal of Economic Perspectives 29, 1, 2015. Traducción de Alberto Supelano; se publica con las autorizaciones correspondientes. Fecha de recepción: 30 de agosto de 2015, fecha de aceptación: 29 de octubre de 2015. Sugerencia de citación: Fourcade, M.; E. Ollion y Y. Algan. "La superioridad de los economistas", Revista de Economia Institucional 17, 33, 2015, pp. 13-43. DOI: http:// dx.doi.org/10.18601/01245996.v17n33.02 
A primera vista, el mercado de trabajo académico parece confirmar el juicio endogámico sobre el estatus más alto de los economistas. Son los únicos científicos sociales que tienen un premio "Nobel”, gracias a una beca del Banco de Suecia a la fundación Nobel. Predominan en los niveles más altos de remuneración en las facultades estadounidenses de Artes y Ciencias, según datos del Bureau of Labor Statistics. De hecho, "ganan más y tienen mejores perspectivas de carrera" que los físicos y matemáticos (como dijo Freeman); solo les va mejor a los graduados en informática y a los ingenieros. A diferencia de los académicos de ciencias teóricas y humanidades, los economistas famosos tienen la oportunidad de obtener ingresos por consultoría, inversiones y compañías privadas, y participación en juntas directivas empresariales. Weyl (de próxima publicación) documenta que el $40 \%$ del ingreso de los autores en finanzas y organización industrial proviene de la consultoría, bien sea en empresas (finanzas) o en el gobierno (OI). En 2010, el documental Inside Job reveló las relaciones lucrativas y quizá complacientes entre algunos de los miembros más distinguidos de la profesión y las nebulosas financieras que rodean a Wall Street.

\section{Gráfica 1}

Porcentaje de mujeres doctoradas en disciplinas seleccionadas, 1966-2011

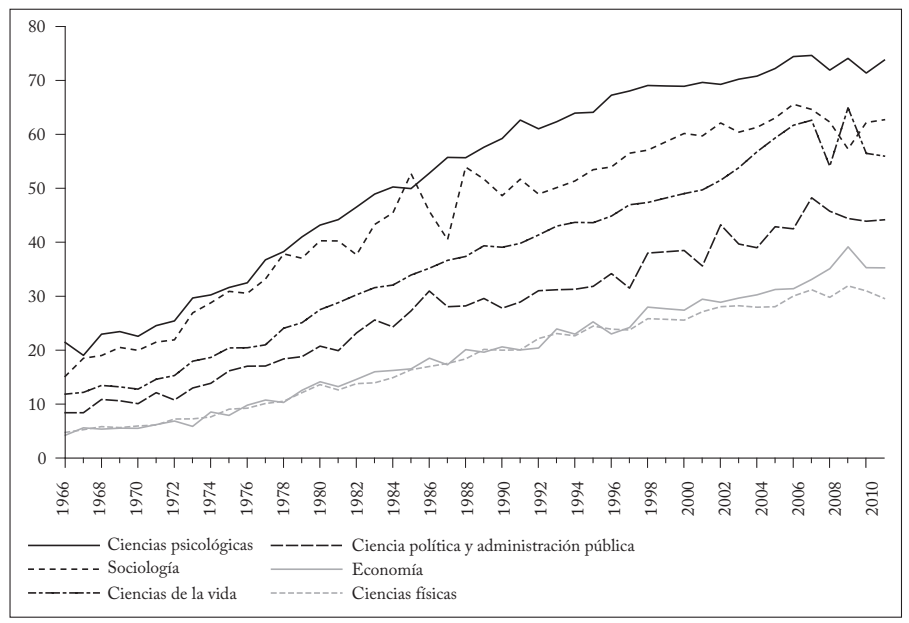

Fuente: U. S. National Center for Education Statistics, Integrated Post-Secondary Education Data System Completion Survey.

Esta mejor situación financiera de los economistas, sobre todo en las principales universidades, junto con el énfasis de la disciplina en el dominio del razonamiento cuantitativo (interpretado como signo de mayor capacidad intelectual), respalda su frecuente actitud despectiva 
hacia las demás ciencias sociales, menos formales. Pero hay otras razones para las distantes relaciones entre científicos sociales. Primera, la composición social es diferente. En la autoselección de cada disciplina inciden fuertemente los atributos sociales. Por ejemplo, en economía, así como en física o filosofía pero en marcado contraste con la sociología, predominan los hombres (gráfica 1). Así, las relaciones entre disciplinas reflejan inevitablemente diferencias más amplias, de género, estratificación y desigualdad. Y aunque no tenemos buenos datos para comparar el origen social de los científicos sociales en Estados Unidos (aunque ver Bourdieu, 1984, y Lebaron, 2000, sobre Francia), podemos decir que las disparidades en las actuales condiciones materiales de los diversos campos generan fuertes disparidades en el estilo de vida y la visión del mundo así como en sus tensas relaciones.

Segunda, en las ciencias sociales ha habido un rápido crecimiento demográfico desde la Segunda Guerra Mundial, que ha provocado diferenciación interna e híper especialización (Abbott, 2001; Frank y Gabler, 2006). Este proceso ha oscurecido la herencia común -el hecho de que la historia y la filosofía moral dieron origen a la economía política en el siglo XIX (ver Haskell, 1977, y Ross, 1991, para un análisis centrado en Estados Unidos), mientras que la sociología estadounidense surgió en parte de la economía a comienzos del siglo XX (Young, 2009).

En este ensayo exploramos la cambiante relación entre la economía y las demás ciencias sociales en cuatro dimensiones específicas. Primero documentamos la insularidad relativa de la economía y su posición dominante en la red de las ciencias sociales en Estados Unidos. Aunque todas las disciplinas son de algún modo insulares - una consecuencia de la mayor división del trabajo académico (Jacob, 2013)-, este rasgo caracteriza particularmente a la economía. Luego documentamos la pronunciada jerarquía existente en la disciplina, en comparación con otras ciencias sociales. La autoridad ejercida por los jugadores más poderosos, que fomenta la cohesión intelectual y el manejo de los asuntos internos de la disciplina, tienen pocos equivalentes en otras partes. En tercer lugar examinamos la cambiante red de afiliaciones de la profesión en el periodo posterior a la Segunda Guerra Mundial y, en particular, mostramos que las transformaciones en la enseñanza superior (sobre todo el ascenso de las escuelas de negocios) y en la economía han contribuido a reorientar la economía hacia temas de negocios, en especial de finanzas. Por último, exponemos algunas ideas sobre la situación material, la visión del mundo y la influencia social de los economistas, que también los apartan de 
sus pares académicos. En conjunto, estos rasgos ayudan a definir y a explicar su autoconfianza intelectual y, a la vez, sus pretensiones asertivas en asuntos de política pública.

Cuando nos referimos a la "superioridad de los economistas", el double entendre tiene un propósito descriptivo y explicativo. La economía ocupa una posición única entre las disciplinas académicas. Se caracteriza por pretensiones científicas de gran alcance ligadas al uso de métodos formales, al estricto manejo de la disciplina de arriba hacia abajo, a la alta demanda de sus servicios en el mercado, sobre todo de partes poderosas y ricas, y a la alta remuneración. Esta posición de superioridad social también alimenta la confianza en ella misma, hace posible que mantenga su insularidad epistemológica relativa y alienta la inclinación natural a sentirse con derechos. Aunque la expansión imperialista de la economía en aspectos de la ciencia social que solían estar fuera del canon económico ha impulsado algún compromiso con las disciplinas no económicas, el patrón de intercambio sigue siendo muy asimétrico, y a cambio provoca resentimiento y hostilidad. Y aunque la posición de los economistas les da un poder inusual para lograr cambios en el mundo, también los expone más a conflictos de interés, a la crítica y a la burla cuando las cosas van mal.

\section{INSULARIDAD}

Las trayectorias intelectuales de las ciencias sociales se alejaron visiblemente en el periodo de posguerra. La economía cambió desde su juventud continental. Dejó atrás la historia y giró hacia los campos paradigmáticos en ciencias naturales como la física, para emularlos (Mirowski, 1989). A diferencia de sus precursores más literarios, los economistas de hoy en día atribuyen su prestigio intelectual y su autonomía al uso de medidas y modelos precisamente especificados y parsimoniosos. Ven los altos costos técnicos de entrada al campo y el empeño de sus miembros por captar complicados procesos sociales mediante ecuaciones o una clara causalidad como prueba del mayor compromiso científico de la disciplina, y reivindican su distancia y la falta de compromiso de las ciencias sociales más discursivas. Un ejemplo conocido es el de Lazear, quien afirmó:

El ascenso de la economía es el resultado del hecho de que nuestra disciplina tiene un lenguaje riguroso que permite expresar conceptos complicados en términos relativamente simples y abstractos. Este lenguaje permite reducir la complejidad. La complejidad puede ampliar la riqueza de la descripción, pero también impide que el analista vea lo que es esencial (2000,99-100). 
Un eminente profesor hizo eco a esta opinión cuando describió, esta vez de modo crítico, las estrechas exigencias epistemológicas de su disciplina:

Se supone que solo se deben seguir ciertas reglas. Si no se siguen ciertas reglas no se es economista. Esto significa que el comportamiento de las personas se debe deducir de la teoría estricta de la maximización [...] Lo contrario [a ser axiomático] sería argumentar mediante ejemplos. No se tiene permiso para hacer eso [...] Hay un término para eso: "eso es anecdótico". Estás terminado si la gente ha dicho que eres anecdótico [...] Lo que hoy se dice en términos modernos es: "Esto no se ha identificado". Oh, Dios, cuando tu causalidad no es identificada estás terminado (entrevistado por Fourcade, 2009, 91).

Durante buena parte del periodo de posguerra, el principal camino para afirmar la pureza científica en economía era tensionar los músculos matemáticos y estadísticos y reducir la argumentación a un conjunto formal y parsimonioso de ecuaciones. Con la revolución empírica de las décadas de 1990 y 2000, esta función se trasladó al enfoque duro de la causalidad centrado en el diseño de la investigación y la inferencia, a menudo ensalzando las virtudes de los experimentos controlados aleatoriamente (ver, p. ej., Angrist y Pischke, 2010). Aunque este paso no ha escapado a la crítica (ver, p. ej., Leamer, 2010, y Sims, 2010), es un alejamiento importante de la hoy desacreditada orientación súper teórica de los años setenta y ochenta. Pero el paso a la microeconomía aplicada, aunque real, no amplió notablemente las conexiones con otras disciplinas. Los economistas empezaron a considerar temas tradicionalmente asociados con la sociología, la ciencia política y la psicología: las instituciones políticas, la estructura familiar, los efectos de vecindario, la influencia de los pares o (más tarde) la movilidad social. Pero las citas referentes a otras disciplinas siguen mostrando la insularidad relativa de la economía. Por supuesto, un hecho notable en las ciencias sociales de Estados Unidos (Europa continental tiende a ser más ecuménica) es el grado en que todas trabajan en aislamiento relativo: la economía, la sociología, la ciencia política y la psicología tienen altos porcentajes de citas de la misma disciplina. Pero la economía las supera notablemente con un $81 \%$ de citas de su mismo campo en 1997, frente al 52\% en sociología, al 53\% en antropología y al $59 \%$ en ciencia política ${ }^{1}$.

Las principales razones de la insularidad de la economía tienen que ver con la visión epistemológica de cada ciencia social y la desigualdad del poder entre ellas. En primer lugar, la teoría de la acción al estilo de los economistas no es compatible con la premisa básica de gran

1 Ver Jacobs (2013, 82), que utiliza los NSF Science and Engineering Indicators 2000, anexo en línea 6-54, basado en una muestra de las revistas más citadas en cada campo . 
parte de las ciencias humanas, a saber, que los procesos sociales dan forma a las preferencias individuales (y no a la inversa). En economía, en cambio, “de gustibus non est disputandum”(Stigler y Becker, 1977)2: usualmente supone que las preferencias "son fijas" (Baron y Hannan, 1994,1116) ${ }^{3}$. En segundo lugar, los métodos cualitativos que sustentan las interpretaciones de muchos científicos sociales no encajan bien con las aspiraciones formales de los economistas, con su visión de la causalidad ni con su predilección por la precisión metodológica y teórica frente a la precisión en el mundo real. En tercer lugar, aunque los terrenos básicos se traslapan, el orden jerárquico explícito o implícito entre las disciplinas a menudo depende del tipo deseable de compromiso intelectual.

Cuadro 1

Citas en las revistas emblemática de artículos publicados en las 25 principales revistas de cada disciplina, 2000-2009

(Porcentaje del total de citas en cada revista)

\begin{tabular}{lcccc}
\hline & \multicolumn{3}{c}{ Revistas citadas } & \\
\cline { 2 - 4 } $\begin{array}{c}\text { Revista en la que } \\
\text { aparece la cita }\end{array}$ & $\begin{array}{c}25 \text { principales } \\
\text { revistas de } \\
\text { economía }\end{array}$ & $\begin{array}{c}25 \text { principales } \\
\text { revistas de ciencia } \\
\text { política }\end{array}$ & $\begin{array}{c}25 \text { principales } \\
\text { revistas de } \\
\text { sociología }\end{array}$ & $\begin{array}{c}\text { Número total de } \\
\text { artículos/citas de } \\
\text { esta revista }\end{array}$ \\
\hline AER & 40,3 & 0,8 & 0,3 & $907 / 29.958$ \\
APSR & 4,1 & 17,5 & 1,0 & $353 / 19.936$ \\
ASR & 2,3 & 2,0 & 22,0 & $399 / 23.993$ \\
\hline
\end{tabular}

Nota: el alto número de artículos y de citas en la $A E R$ se debe a los Papers and Proceedings. Si estos se excluyen el patrón no es significativamente diferente.

Fuente: Scientific Information's Web of Social Sciences, compilación de los autores.

El examen detallado de las citas revela grandes diferencias entre disciplinas. En una revisión de revistas académicas de 1995 a 1997, Pieters y Baumgartner (2002) encontraron patrones de citas fuertemente asimétricos entre la economía y las demás ciencias sociales. Nuestro análisis de las citas en revistas emblemáticas de economía, sociología y ciencia política del periodo 2000-2009 confirma ese resultado. Como muestra el cuadro 1, en la American Political Science Review (APSR) las citas a las 25 principales revistas de economía son más de cinco veces mayores que las citas en la American Economic Review (AER) a las 25 principales revistas de ciencia política. La asimetría es aún más marcada con respecto a la American Sociological Review (ASR). Mien-

2 "En cuestión de gustos no hay disgustos".

${ }^{3}$ Sin embargo, en los últimos diez a quince años, algunos economistas han mostrado un interés más activo en la formación de las preferencias; ver Bowles (1998), y Fehr y Hoff (2011). 
tras que el 2,3\% de las citas de los sociólogos aluden a economistas (a menudo en forma crítica), apenas el 0,3\% de los economistas citan sociólogos (considerando únicamente las 25 principales revistas de cada disciplina). Es posible que los datos estén sesgados hacia abajo debido a que en sociología y ciencia política las citas suelen ser más amplias y debido al papel de los libros (que aquí no contabilizamos) en esas disciplinas. Aun así, vale la pena reflexionar sobre esta asimetría, porque la discrepancia es muy grande y otras fuentes apuntan en la misma dirección. Una comparación selectiva de citas de autores importantes en sociología y en economía que se ocupan expresamente de la otra disciplina también muestra ese patrón. E1 sociólogo francés Pierre Bourdieu, el nombre más citado en la sociología actual de Estados Unidos, solo recibió una mención en la $A E R$ en la década de 2000 (frente a 60 en la $A S R$ ), mientras que Gary Becker obtuvo 41 citas en la $A S R$ (106 en la $A E R$ ). En esa misma década Max Weber y Mark Granovetter recibieron cada uno cuatro menciones en la $A E R$, pero James Heckman fue citado 25 veces por sociólogos en la $A S R$; y Oliver Williamson, 13 veces $^{4}$.

Desde el punto de vista de los sociólogos, geógrafos, historiadores, politólogos e incluso los psicólogos, los economistas se asemejan a colonos que se establecen en su tierra; una imagen reforzada por la orgullosa pretensión de "imperialismo económico" de algunos de ellos (Lazear, 2000). Atraídos por la perspectiva de una abundante cosecha, los economistas se lanzan a explorar los nuevos terrenos. Pueden pedir orientación a la llegada e incluso asociarse con gente local (con la que a menudo comparten los mismos datos). Pero es poco probable que aprendan mucho de ella, ya que suelen preferir sus propias técnicas ${ }^{5}$. $\mathrm{Y}$, en algunos casos, solo se asocian con el propósito de rectificar a las otras disciplinas (Nik y van Horn, 2012). Especialmente por influencia de la escuela de Chicago, el paradigma económico dominante ha conquistado algunos segmentos de la ciencia política, el derecho, la contabilidad y la sociología (durante algún un tiempo) bajo la etiqueta de teoría de la elección racional, lo que explica en parte la dirección de las pautas de citación antes mencionadas.

Las encuestas de opinión confirman aún más este análisis. E1 cuadro 2 sugiere que los economistas valoran menos la interdisciplinariedad que los miembros de otras disciplinas e incluso que sus colegas de las escuelas de negocios. Son los únicos de este grupo cuya

${ }^{4}$ Los datos provienen de una investigación en curso sobre ciencias sociales. Para los resultados preliminares, ver Ollion y Abbott (de próxima publicación).

${ }^{5}$ Aunque a veces también adaptan la técnica de otros, como ilustra la adopción del análisis de redes de la sociología. 
gran mayoría discrepa o discrepa fuertemente de la afirmación que se menciona en el cuadro. Estos resultados son consistentes con la idea de que los economistas, con su confianza característica en la superioridad de su disciplina, son menos propensos a sentir la necesidad de apoyarse en otras disciplinas e incluso a reconocer su existencia.

\section{Cuadro 2}

Acuerdo o desacuerdo en que: "En general, el conocimiento interdisciplinario es mejor que el conocimiento obtenido por una sola disciplina" (Porcentaje)

\begin{tabular}{lccc}
\hline Profesores de & $\begin{array}{c}\text { De acuerdo/ } \\
\text { muy de acuerdo }\end{array}$ & $\begin{array}{c}\text { En desacuerdo/ } \\
\text { muy en desacuerdo }\end{array}$ & $\begin{array}{c}\text { Sin respuesta/ } \\
\text { no sé }\end{array}$ \\
\hline Economía & 42,1 & 57,3 & 0,6 \\
Sociología & 72,9 & 25,3 & 1,8 \\
Ciencia política & 59,8 & 28,0 & 12,2 \\
Psicología & 78,7 & 9,4 & 11,9 \\
Finanzas & 86,6 & 9,6 & 3,8 \\
Historia & 68,2 & 31,7 & 0,1 \\
\hline
\end{tabular}

Fuente: encuesta de Gross y Simmons a profesores universitarios estadounidenses sobre política, realizada en 2006 a una muestra de 100 profesores por cada disciplina. La proporción que la respondió es baja (aunque no tanto en este tipo de encuestas) y varió entre disciplinas (economistas: 44\%; sociólogos: 55\%; politólogos: 54\%; psicólogos 49\%; profesores de finanzas: $37 \%$; historiadores: 54\%). Agradecemos a Neil Gross por las tabulaciones cruzadas de esta encuesta y por su ayuda en otras partes del artículo. Para más información sobre la encuesta, ver Gross y Simmons (2007), y para un análisis más amplio, Gross (2013).

Como bien saben los sociólogos, así suele ocurrir en situaciones desiguales: quienes ocupan una posición central en un campo no perciben a los actores periféricos y son bastante inconscientes de los principios en que se basa su predominio (Bourdieu, 1984). En cambio, tienden a racionalizar el poder y la desigualdad como un "simple" producto del mérito, justificado por el esfuerzo o el talento. Un buen ejemplo de este tipo de racionalización es mencionar el alto puntaje promedio en el GRE de los estudiantes de posgrado en economía o los altos factores de impacto de las revistas de economía. Los sociólogos podrían señalar que en esas diferencias entre disciplinas influyen fuertemente determinantes sociales como la clase, el género y la raza. Entre tanto, los actores periféricos se orientan compulsivamente hacia los actores dominantes, bien sea positiva o negativamente ${ }^{6}$.

\section{LA JERARQUÍA INTERNA}

Para explicar estas relaciones asimétricas se suele evocar la estructura intelectual dentro de la disciplina: como los economistas han logrado

${ }^{6}$ Un ejemplo de este fenómeno general es que los académicos extranjeros son más propensos a definir su identidad en torno al reconocimiento que reciben (o no reciben) de instituciones académicas estadounidenses que a la inversa (Fourcade, 2006). 
preservar un núcleo disciplinario más unitario que otras ciencias sociales, es más fácil que estas hagan referencia a la economía - así solo sea para discutir sus argumentos- que a la inversa. En otras palabras, los argumentos de una disciplina unitaria son identificables desde fuera, mientras que los de una disciplina díscola son más inciertos. El cuadro 1 muestra que las citas en American Economic Review son menos interdisciplinarias y más concentradas que las citas en las revistas emblemáticas de ciencia política y sociología. Esto sugiere que la economía, más que las otras disciplinas, mira hacia dentro y hacia la cima de su jerarquía interna. Lo que se puede interpretar de dos maneras: hay más consenso en economía que en sociología o en ciencia política, y hay más control. Estas dos interpretaciones no son excluyentes: puede haber más consenso porque hay más control (p. ej., si quienes controlan las principales revistas promueven una visión coherente de lo que es la buena investigación); a la inversa, el control puede ser más efectivo y obligatorio porque hay más consenso.

Hay abundante evidencia de que a pesar de las profundas diferencias políticas entre ellos, es más probable que los economistas piensen en un marco fuertemente integrado y unificado que otros científicos sociales. Por ejemplo, coinciden ampliamente en el conjunto básico de principios y herramientas que estructuran la formación de doctorado. También recurren a los manuales mucho más que las otras ciencias sociales, incluso en el doctorado; y los manuales de posgrado tienden a ser escritos por profesores de departamentos de élite. En una encuesta realizada en 1990 se encontró que la educación de posgrado era "sorprendentemente similar" en los programas de doctorado de economía (Hansen, 1991, 1.085).

En los comités interdisciplinarios de asignación de becas que estudió Lamont (2009), los economistas tenían normas internas de evaluación más homogéneas, más confianza en sus juicios sobre la investigación de excelencia aun en otros campos, y mayor probabilidad de votar como grupo que los miembros de otras disciplinas ${ }^{7}$. Solo los historiadores se les asemejaban en la coherencia y la cohesión de sus juicios sobre el buen trabajo histórico, pero tenían más divisiones internas por razones políticas y eran más abiertos a considerar diversos criterios cuando juzgaban a otras disciplinas. Los juicios sobre el mérito académico de las propuestas eran más

\footnotetext{
${ }^{7}$ En su estudio de la manera en que los economistas convencionales establecieron su posición en la Escuela de Estudios Avanzados en Ciencias Sociales (EHESS) de París, Godechot (2011) encontró un patrón similar de fuerte cohesión interna $\mathrm{y}$ relaciones asimétricas y excluyentes con los de fuera.
} 
dispersos y menos consensuales en las humanidades y otras disciplinas sociales, lo que hacía más difícil identificar obras importantes de dentro y de fuera.

En cuanto al control, los economistas manejan rígidamente su disciplina. Desde hace tiempo los estudiosos han señalado que los principales departamentos de economía ejercen fuerte influencia en el mercado de trabajo de la disciplina (Cole, 1983; Whitley, 1984). El estudio empírico más convincente sobre este aspecto proviene de la comparación que hizo Han (2003) del proceso de contratación en siete disciplinas (de su "régimen tribal"): dos de humanidades -historia e inglés-, cuatro de ciencias sociales -economía, ciencia política, psicología y sociología- y matemáticas. Usando compilaciones anuales de Lingua Franca en Pistas de empleo: ¿qquién fue contratado y dónde? (1993-2000), Han encontró, como era de esperar, que todas las disciplinas siguen un "principio de prestigio": la contratación depende fuertemente del prestigio de los departamentos reportado por fuentes como el Consejo Nacional de Investigación y US Nerws and World Report. E1 flujo de estudiantes entre departamentos proporciona evidencia inequívoca: las universidades solo contratan egresados de instituciones clasificadas en los niveles alto o superior. De ahí que la academia se parezca a los sistemas de parentesco descritos por Lévi-Strauss (1969), en los que se prefieren ciertas alianzas (entre estudiantes y departamentos) mientras que otras, por ser tabúes, simplemente no pueden existir. Pero esta correlación entre prestigio y ubicación es más fuerte en economía. Allí, la distinción entre grupos es más tajante que en cualquier otra disciplina. Los departamentos de economía del nivel superior del orden jerárquico intercambian estudiantes en mayor proporción que en otros campos, incluidas las matemáticas. Surgen tres conclusiones. Primera, la jerarquía es definida mucho más claramente en economía. Segunda, el campo de la economía es horizontalmente más integrado, con fuertes normas de reciprocidad y cohesión en el proceso de contratación. Tercera, estas normas mantienen la gran estabilidad de la jerarquía de prestigio de los departamentos a través del tiempo. En contraste, la psicología y la sociología son los campos más descentralizados y menos cohesionados, y sus clasificaciones de prestigio son menos estables.

\section{PRÁCTICAS DE EMPLEO}

El comportamiento del mercado anual de empleo para recién egresados confirma estas diferencias entre las ciencias sociales. En economía, 
el proceso es muy organizado y la mayoría de los departamentos deciden colectivamente la clasificación de sus estudiantes que solicitan empleo. Este procedimiento, poco común en muchos campos académicos, solo es posible en el contexto del fuerte acuerdo entre los economistas sobre criterios de calidad y debido a que creen que los procesos de búsqueda y de colocación pueden ser más eficientes de esa manera, sin alterar los resultados. Una vez el departamento clasifica a sus estudiantes, se delega a intermediarios del mercado ("funcionarios de colocación") la tarea de ayudar a colocarlos, vendiendo en forma activa los productos en oferta (por decirlo así) a los posibles compradores. Por último, un proceso de evaluación ritual filtra gradualmente a los candidatos aprobados, empezando con las entrevistas en las reuniones anuales de la ASSA celebradas a comienzos de enero. Para los aspirantes que acaban de doctorarse, la acción real en la conferencia de la ASSA tiene lugar en las suites del hotel, donde los contratantes -otros departamentos, y también agencias del gobierno, entidades internacionales y empresas del sector privado- entrevistan a los candidatos un día tras otro. Entre tanto, en las salas de reuniones públicas, los académicos establecidos presentan sus trabajos a sus pares.

E1 mercado de trabajo para recién graduados en sociología está en abierto contraste con esta cuidadosa orquestación de la circulación de estudiantes. Para los solicitantes de empleo y los profesores de sociología la noción de un proceso administrado colectivamente para encajar estudiantes y puestos de trabajo sería inviable en la práctica y objetable en principio. Es cierto que las redes sociales cumplen un papel y que los contactos informales a veces preceden a las "presentaciones personales", pero rara vez toman la forma de una entrevista realizada por un comité en pleno, como se hace en economía. La jerarquía entre departamentos de sociología también es más incierta. Sí existe una estructura vertical; los sociólogos también tienen "estrellas" de mercado y están atentos a las clasificaciones de los departamentos mencionadas comúnmente. Pero se pasarían apuros para definir los principios en que se basa el orden jerárquico en la disciplina. Desprovistos de criterios consensuales para montar una jerarquía putativa, y quizás también menos confiados en el juicio de sus colegas, los sociólogos deben mantener más abierto el proceso para construir consensos, incluso desde abajo. En economía, el consenso es mucho mayor desde el principio; la "información" sobre los candidatos se considera homogénea y, por tanto, intrínsecamente confiable. En consecuencia, la gama de opciones posibles se define y determina más estrechamente mucho antes. 


\section{PRÁCTICAS DE PUBLICACIÓN}

El mercado de publicaciones de economía también es más concentrado que en otras ciencias sociales, en el sentido de que las revistas más citadas muestran una mayor concentración de artículos provenientes de departamentos de élite. Tanto de los departamentos donde trabajan los autores como de los departamentos donde se graduaron. Por ejemplo, de acuerdo con nuestros cálculos, los cinco principales departamentos de sociología representan el 22,3\% de los autores publicados en el $A J S$, pero los cinco principales departamentos de economía representan el 28,7\% de los autores publicados en el JPE y el 37,5\% en el OJE. El contraste es aún más marcado cuando se pasa a los lugares donde los autores obtuvieron el doctorado, pues los cinco principales departamentos de sociología ahora totalizan el 35,4\% en el $A J S$, pero el 45,4\% en el JPE y un elevado 57,6\% en el $Q J E$.

Un economista podría sostener que esta concentración es evidencia de que, en los departamentos de economía, la fuerza intelectual está más concentrada en los principales departamentos que en el caso de los departamentos de sociología. Los miembros de otras disciplinas podrían destacar métricas alternativas que también se usan en la evaluación (en algunas los libros pueden ser más importantes) y la existencia de numerosos criterios de valor que solo se reflejan de modo imperfecto en la jerarquía de las revistas académicas ${ }^{8}$. Los economistas, en cambio, suelen ver las jerarquías institucionalizadas como indicadores emergentes y veraces de algún valor subyacente, y por eso están obsesionados con ellos. En ninguna otra ciencia social se puede encontrar el enorme volumen de datos e investigaciones sobre clasificaciones (de revistas, departamentos e individuos) que producen los economistas, para no mencionar la centralización de la investigación económica en RePEc (un archivo de investigación internacional) y la existencia de un área significativa aunque marginal: la historia de la economía.

Esta aguda conciencia de la jerarquía provoca una feroz competencia por el estatus personal, que puede explicar algunos de los aspectos más inquietantes de los procedimientos operativos en ese campo. Un hecho notable es que algunas revistas reputadas editadas en ciertas universidades tienen una demostrable preferencia por autores de esas mismas universidades, mientras que la American Economic Review es mucho más balanceada en la asignación de su espacio. En su revisión

\footnotetext{
${ }^{8}$ Sobre el papel de los libros en la carreras académica de los sociólogos, ver Clemens et al. (1995). Aunque los datos utilizados en ese estudio son de hace 20 años, no hay evidencia de que la situación de dos puntas haya cambiado mucho.
} 
de las cifras de este sesgo desde 1950, Coupé $(2004,27)$ encuentra una consistente sobre representación de autores locales. Entre 1990 y 2000, por ejemplo, el QJE, con sede en la Universidad de Harvard, "asignó el 13,4\% de su espacio a su propia gente" y un 10,7\% al vecino MIT (contra el 8,8\% al siguiente departamento más reputado, Chicago). En cambio, el 9,4\% de las páginas del JPE, con sede en Chicago, se dedicó a autores afiliados a Chicago, una proporción similar a la suma de las que asignó a los de la Universidad de Harvard y del MIT (4,5\% y 5,1\%, respectivamente). Wu (2007) muestra que el sesgo aumentó entre 2000 y $2003^{9}$. Nuestros datos (2003-2012) confirman este dominio de Cambridge, Mass., en el QJE y (en menor medida) de Chicago sobre el JPE. La supremacía de Cambridge es aún más llamativa cuando se observa dónde obtuvieron sus doctorados los autores. En 2003-2012, la proporción de graduados en Harvard que publican en el OJE fue del 20,5\%, algo mayor que la de los graduados en el MIT (16,4\%). Ambas muy superiores a la del tercer colaborador, Princeton (7,4\%). En el JPE, los graduados de Harvard, MIT y Chicago representan, cada grupo, entre el 10\% y el 11\%.

Hay muchas razones para el sesgo doméstico en las revistas de economía, como el mayor nivel de envío de artículos de profesores y estudiantes de doctorado (o de ex doctorados) si la revista se edita en la sede; la mayor probabilidad de ser alentados por el editor, parte de cuya tarea es conseguir buenos trabajos mediante conexiones interpersonales (Laband y Piette, 1994; Medoff, 2003); o la inclinación de la revista, que provoca sesgos de autoselección en el envío de artículos. Pero en otros campos ocurren procesos similares sin producir esos efectos dramáticos. Por tanto, aunque la estructura social del campo explique algunas de estas diferencias, no las explica del todo: esa misma estructura se sitúa en el núcleo del fenómeno que nos interesa: la continua supremacía de tres departamentos -Chicago, Harvard y el MIT- sobre todos los demás, reforzada mediante el control de dos revistas universitarias. Como punto de comparación, ese sesgo es prácticamente inexistente en la principal revista de sociología editada por un departamento universitario, el $A J S$, con sede en la

\footnotetext{
${ }^{9} \mathrm{Wu}$ (2007) encontró que el 14\% de las páginas publicadas en el JPE en ese periodo fue de autores de Chicago; y la friolera del 28\% de las páginas del QIE, de autores de Harvard-MIT (15\% de la Universidad de Harvard y 13\% del MIT). Nuestros datos del periodo 2003-2012 muestran que la Universidad de Chicago aún ocupa el primer lugar con el 10,8\% del total de autores publicados en el $J P E$, seguida de Harvard $(6,1 \%)$ y del MIT $(4,1 \%)$. En el mismo periodo, el QIE publicó casi el doble de autores $(14,9 \%)$ de la Universidad de Harvard que de Chicago (7,0\%); el MIT fue el tercero $(6,2 \%)$.
} 
Universidad de Chicago ${ }^{10}$. Esto sugiere que el sesgo doméstico en las principales revistas de economía y la estabilidad de la clasificación de los principales departamentos no son una simple coincidencia de la geografía y de los autores, sino que provienen de una forma particular de organización y control social.

\section{PRÁCTICAS DE ASOCIACIÓN}

Por último, la observación de las asociaciones profesionales en ciencias sociales confirma la organización más cohesionada y jerárquica de la economía, y el carácter más díscolo de las disciplinas hermanas. Una rápida comparación de los estatutos de la American Economic Association (AEA), la American Sociological Association (ASA) y la American Political Science Association (APSA) muestra grandes disparidades en la distribución del poder político entre disciplinas. A pesar de sus 18.000 miembros, la AEA es una organización minimalista con sede en Nashville, Tennessee. Las cuotas son bajas, de 20 a 40 dólares al año desde 2014. Los estatutos son breves, 1.770 palabras, y los procedimientos están centralizados. Solo hay seis funcionarios elegidos, y en general solo se presenta un candidato a presidente. Como muestra la gráfica 2, los líderes de la AEA provienen en forma desproporcionada de los departamentos de élite: el $72 \%$ de los miembros no elegidos del consejo de la AEA proviene de los cinco principales departamentos, y solo el $12 \%$ y el $20 \%$ en la APSA y la ASA, respectivamente. El presidente y el comité de programas organizan las reuniones anuales, lo que implica seleccionar de antemano las sesiones y los artículos a partir del subconjunto de sesiones que se incluirán en el volumen de "Papers and Proceedings" de la AER (la edición de mayo después de la reunión anual). Este procedimiento garantiza la popularidad de los temas y autores que los líderes de la organización consideran más importantes.

Este enfoque contrasta con el carácter internamente más balcanizado y más popular de la Asociación Americana de Sociología (ASA) y la Asociación Americana de Ciencia Política (APSA). Aunque estas tienen menos miembros que la AEA (cerca de 15.000 la APSA y de 13.000 la ASA), su planta de personal es más grande. Los procedimientos son más complejos, como se refleja en la longitud de sus estatutos: 4.657 palabras en la ASA y 5.529 en la APSA. Mientras

${ }^{10}$ En todo caso, nuestros datos sugieren que puede haber en cambio un sesgo en contra del profesorado de Chicago en American Journal of Sociology, que apenas está entre los 20 primeros, con apenas el 1,4\% de los artículos publicados. Aunque esta proporción sube al 6,9\% para los ex graduados de Chicago, todavía está por debajo de los doctorados en Harvard $(9,4 \%)$ y Stanford $(8 \%)$. 
Gráfica 2

Composición del consejo ejecutivo de tres organizaciones

Según la clasificación de los departamentos de los funcionarios no elegidos 2010-2014

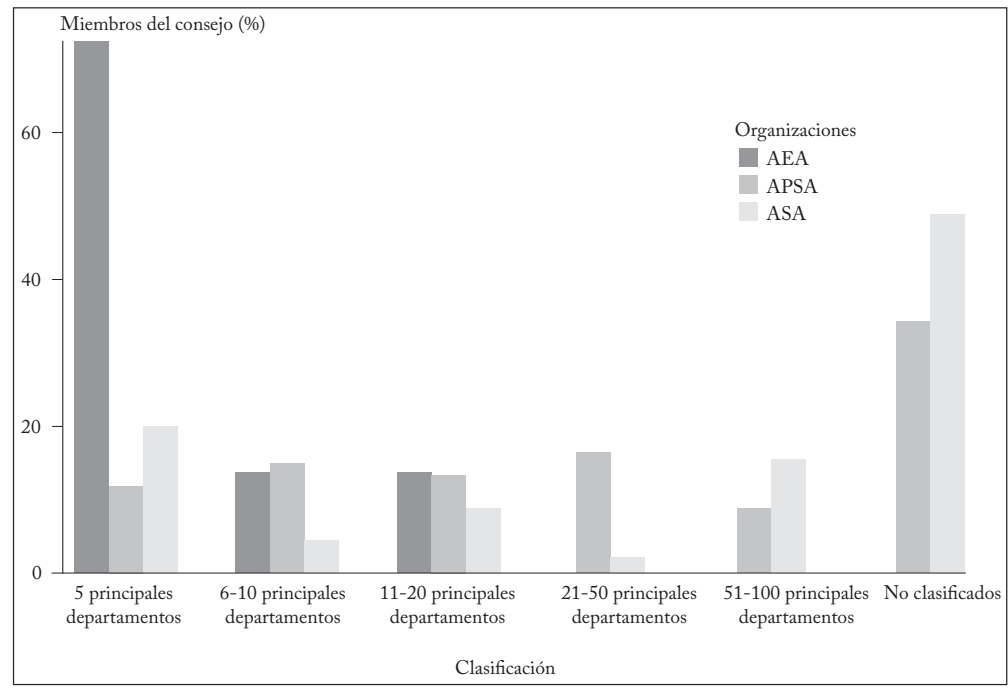

Notas: la clasificación de los departamentos se basa en la clasificación de U. S. News and World Report 2012 de las mejores escuelas de posgrado, por disciplina. La categoría "no clasificado" incluye ante todo departamentos que no tienen programa de posgrado, y un bajo número de instituciones extranjeras.

que la AEA es una organización unitaria, la vida comunitaria entre los sociólogos y politólogos gira en torno a “secciones” o áreas, cada cual con sus propios procedimientos, cuotas, premios y programas en la reunión anual. La ASA resuelve el problema político de las divisiones internas mediante elecciones abiertas, tanto a nivel central como de sección, y la APSA suele recurrir al tira y afloje institucionalizado entre los grupos dominantes. En ambas, los líderes de la organización provienen ante todo de instituciones que no forman parte de la élite, como muestra la gráfica 2. Debido a que el núcleo de la disciplina es menos identificable y más controvertido, los miembros de la ASA y de la APSA se identifican menos con él: los miembros rasos están menos ligados a la élite y ambas asociaciones cumplen ante todo el objetivo democrático de integración y apertura en todos los ámbitos, el cual se refleja en sus programas de conferencias. Sin embargo, la marginación de la mayoría de los líderes de la asociación en la ASA y la APSA con respecto al núcleo de alto prestigio de la disciplina y del poder político también explica el frenético esfuerzo de ambas organizaciones por conseguir influencia, que se manifiesta, entre otras cosas, en sus sedes en Washington. Para apoyar esa infraestructura más elaborada y costosa, sus cuotas se encuentran entre las más altas de las ciencias 
sociales: de 50 a 350 dólares al año en la ASA y de 40 a 320 dólares en la APSA; sin contar las cuotas de sección.

\section{EL ASCENSO DE LAS FINANZAS}

A pesar de la insularidad y la autonomía relativas de la economía, los economistas aún se relacionan con otras disciplinas. Nuestro análisis de las cinco principales revistas de economía muestra que entre el 19\% y el 25\% de las citas son ajenas a la disciplina, un patrón bastante estable desde finales de la Segunda Guerra Mundial. Pero cuando es interdisciplinaria ¿a dónde recurre? ¿Sus conexiones con otras disciplinas han cambiado con el tiempo?, y de ser así ¿qué nos dice esto de su evolución?

Estas preguntas nos señalan un camino diferente al de la historia reciente de la economía de buena parte de la literatura, que se centra en sus tendencias internas, como el cambio en los patrones de publicación en sus revistas (Card y DellaVigna, 2013), el ascenso y la caída en volumen de sus campos especializados (Kelly y Bruestle, 2011) y de su prestigio relativo (Ellison, 2010), o la tendencia decreciente del uso de las matemáticas y de la publicación de artículos teóricos $(\mathrm{Ha}-$ mermesh, 2013). En vez de ello, empezamos analizando las relaciones entre la economía y otras disciplinas en el tiempo. En otras palabras, partimos del supuesto de que lo que se cita dice algo acerca de quién se es. Encontramos que el cambio en los patrones de citas externas dice mucho de la situación interna de la disciplina y del cambio del poder relativo de sus diferentes componentes.

La gráfica 3 presenta las referencias de la economía a otras disciplinas y se basa en nuestro amplio estudio de las citas en cinco destacadas revistas de economía fundadas mucho antes de la Segunda Guerra Mundial: OJE (en 1899), JPE (en 1899), AER (en 1911), Econometrica (ECTRA, en 1933), y Review of Economic Studies (RES, en 1933$)^{11}$. La gráfica cuenta una historia en parte familiar y en parte menos conocida. Muestra el fuerte aumento del compromiso de la economía con las matemáticas y la estadística en la posguerra, cuyo punto culminante, a mediados de los años setenta, coincide con el punto más bajo del compromiso con otras ciencias sociales (como la ciencia política y la sociología), así como con iniciativas prácticas, como con el derecho y, con un leve retraso, con los negocios. A pesar de los esfuerzos de las fundaciones y del gobierno para promover empeños interdisciplinarios con el rótulo "ciencias del comportamiento" en los años cincuenta, las ciencias sociales se distanciaron claramente

11 Ver los detalles en la nota al pie de la gráfica. 
en los sesenta y setenta. La economía no fue la única fuerza motriz en ese proceso: los experimentos interdisciplinarios en Harvard (Departamento de Relaciones Sociales) y Carnegie-Mellon fracasaron, y las diversas áreas se retiraron a su forma propia de abstracción y alta teoría (Steinmetz, 2005; Isaac, 2010).

Gráfica 3

Citas a otras disciplinas en cinco destacadas revistas de economía

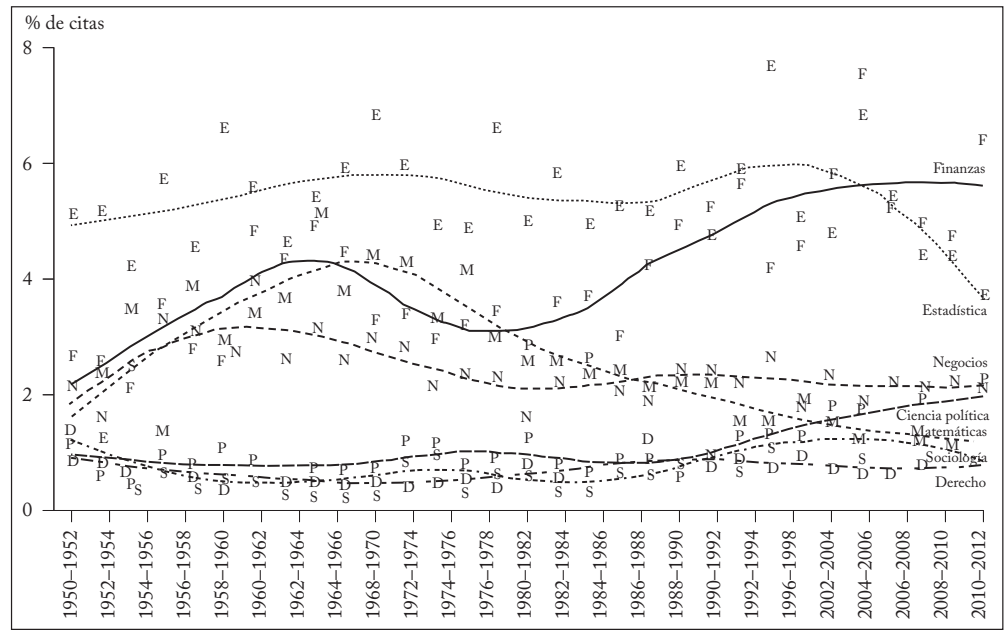

Fuente: datos brutos tomados de Institute of Scientific Information's Web of Social Sciences.

Nota: los puntos de la gráfica muestran la proporción de citas en cinco revistas de economía a revistas de finanzas (F), estadística $(\mathrm{E})$, negocios $(\mathrm{N})$, ciencias políticas $(\mathrm{P})$, matemáticas $(\mathrm{M})$, sociología $(\mathrm{S})$ y derecho $(\mathrm{D})$. Los patrones corresponden a curvas suavizadas mediante un coeficiente de suavización. Para más detalles, ver el Anexo en [http://www.economiainstitucional. com/esp/vinculos/pdf/No33/29010089_data.zip].

La ecología interdisciplinaria que se observa a finales del periodo es muy diferente. Las citas sobre matemáticas prácticamente desaparecieron y las citas sobre estadística disminuyeron. Las otras ciencias sociales reaparecieron, sobre todo la ciencia política (que hizo una conversión parcial a la teoría de la elección racional). Pero la tendencia más llamativa de las últimas décadas es el continuo ascenso de las finanzas como proveedor de referencias "interdisciplinarias” para la economía.

Al juzgar la magnitud de esta tendencia hacia las finanzas es necesario tener en cuenta que la estimación del papel de las finanzas de la gráfica 3 es muy conservadora. Entre las cinco principales revistas no se incluye ninguna revista de finanzas. La gráfica 4 presenta las citas en esas cinco revistas y en dos más: Journal of Finance (JFIN, fundada en 1946) y Economic Journal (EJ, fundada en 1891), con sede en Gran Bretaña, una publicación generalista para economistas 
Gráfica 4

Citas entre seis revistas de economía y una de finanzas

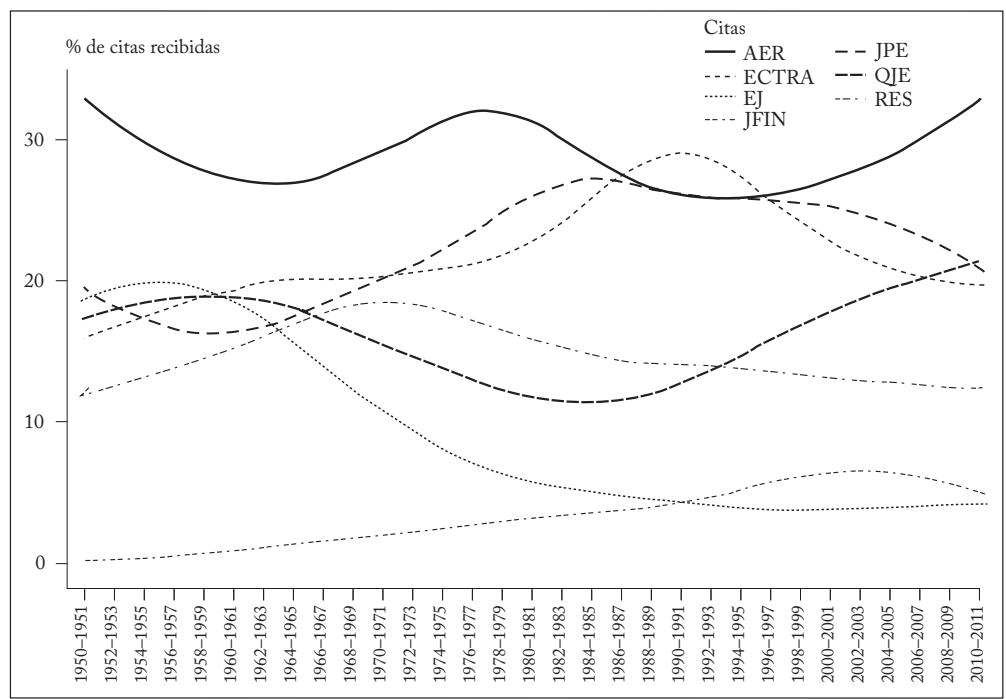

Fuente: datos brutos tomados de ISI's Web of Social Sciences.

Notas: la gráfica 4 presenta un análisis de las citas entre seis revistas de economía - QJE, EJ, JPE, AER, ECTRA, RES- y el $J F I N$. Las citas a sí mismas se excluyen del total de citas cruzadas. Además de los puntos de datos, la gráfica muestra las líneas suavizadas utilizando un coeficiente de suavización. Para más detalles, ver el Anexo en [http://www.economiainstitucional. com/esp/vinculos/pdf/No33/29010089_data.zip].

durante gran parte del siglo $\mathrm{XX}$, a la par del JPE y el $O J E$ a comienzos del periodo. En la gráfica se ve que en 2010-2011, la $A E R$ obtuvo el $33 \%$ de las citas cruzadas. La gráfica muestra grandes cambios en los niveles más altos -el meteórico retorno a la fama del QJE y el declive relativo de Econometrica y del JPE-; otros dos cambios notables en el muy largo plazo son el continuo declive de las revistas británicas (RES y EJ), en particular del EJ (que casi desaparece en el olvido), y el ascenso del JFIN. Nuestros datos de la red bibliométrica (que no se muestran) indican que en la década de 2000, el JF estaba ligado más estrechamente al núcleo de publicaciones estadounidenses, pues recibía entre el $7 \%$ y el $11 \%$ de las referencias cruzadas en $A E R$, $Q J E$ y $J P E$. En otras palabras, el $J F$, que no se habría considerado una revista de economía cuando se fundó, hoy es parte integral de la matriz disciplinaria en economía. Otras revistas de finanzas han seguido su ejemplo a medida que la economía financiera se ha convertido en el enfoque dominante (Jovanovic, 2008) ${ }^{12}$.

12 E1 primer número de Journal of Financial Economics salió en 1974 y hoy es la octava revista de economía por su factor de impacto. Revierw of Financial Studies, publicado por vez primera en 1988, ocupa el décimo segundo. JFIN ocupa el quinto, por encima de la mucho más antigua RES. 
E1 ascenso institucional de las finanzas como fuerza motriz intelectual en economía se remonta a la creación de una base profesoral en las escuelas de negocios en la segunda mitad del siglo XX. En ese periodo, las escuelas de negocios, que controlan la producción de administradores certificados (a través del título de MBA), se transformaron de programas dominados por profesionales que luchaban por la legitimidad académica en grandes empleadores de científicos sociales, y hoy rivalizan con los departamentos académicos tradicionales en el tamaño y la distinción de su profesorado. Una encuesta de 2004 encontró que 549 doctores en economía enseñaban en las 20 mejores escuelas de negocios de Estados Unidos y 637 en los 20 principales departamentos de economía (Blau,2006). Esta absorción de crecientes contingentes de doctores en economía ha convertido a las escuelas de negocios en jugadores formidables en el campo de la ciencia económica, una transformación que atestigua la serie de premios Nobel en economía que desde 1990 se han otorgado a académicos que trabajan en escuelas de negocios ${ }^{13}$.

Nuestro análisis de los artículos publicados en AER desde 1950 revela un rápido aumento de afiliados a escuelas de negocios entre los autores y una fuerte reducción simultánea de autores que trabajan con el gobierno. La participación de los autores cuya principal afiliación es una escuela de negocios aumentó continuamente, de un bajo 3,2\% en 1950 al 17,9\% en la década de 2000. En cambio, las contribuciones de académicos ubicados en agencias del gobierno hoy son marginales ${ }^{14}$.

A medida que el campo académico de la economía se desplaza hacia las escuelas de negocios -y se aleja del gobierno-los economistas enfrentan nuevas circunstancias prácticas, intelectuales y políticas: mayor nivel de remuneración, nuevas conexiones y oportunidades de consultoría y a menudo también diferentes políticas (Jelveh et al., 2014). En los años ochenta aumentaron notablemente las sospechas sobre la acción del gobierno y, sin duda, los economistas suministraron parte de la justificación intelectual al movimiento desregulador en políticas públicas y al uso de los mecanismos de mercado en educación,

${ }^{13}$ Entre ellos Eugene Fama, Oliver Williamson, Robert Engle, Michael Spence, Robert Merton, Myron Scholes, Merton Miller, John Harsanyi y Robert Fogel (ver Fourcade y Khurana, 2013).

${ }^{14} \mathrm{La}$ medición se basa en la afiliación declarada en los artículos que revisamos. Cuando los autores mencionaban varias (algo que ha aumentado con el tiempo), adoptamos el siguiente procedimiento: si había un orden claro, optamos por la primera institución. De lo contrario, para evitar un aumento artificial de la proporción de afiliaciones secundarias, dimos prioridad a los "departamento de economía” cuando se mencionaban junto con otra institución. Para más detalles, ver el Anexo en [http://www.economiainstitucional.com/esp/vinculos/pdf/ No33/29010089_data.zip]. 
transporte, salud, medio ambiente y otras áreas (Blyth, 2002). Los economistas financieros argumentaron enfáticamente que el objetivo de las empresas era maximizar el valor de los accionistas, y dieron una justificación científica a las prácticas gerenciales que favorecía una nueva generación de tiburones corporativos: compras apalancadas, fusiones y adquisiciones, así como la remuneración de los ejecutivos con opciones de compra de acciones ${ }^{15}$. En una crítica reciente de la "extendida captura de los economistas por los intereses comerciales", Zingales encontró que cuando ninguno de los autores trabajaba en una escuela de negocios era "mucho menos probable que [los artículos de economía] respalden el nivel de remuneración de los ejecutivos y mucho más probable que no lo respalden $(2013,139)^{16}$.

\section{UNA VIDA PROPIA}

Los economistas tienen opiniones, creencias y gustos diferentes en comparación con los académicos de otros campos y el público estadounidense en general. La evidencia sobre este tema es dispersa y se debe reunir a partir de diversas fuentes. Una parte considerable proviene de los mismos economistas: la literatura que producen sobre el tema es abundante. La disciplina está plagada de una ansiosa introspección, impulsada por el sentimiento de que los economistas son poderosos pero no amados, y por la sólida evidencia empírica de que son diferentes. En algunos ejemplos clásicos, Marwell y Ames (1981) encontraron que los estudiantes de primer año del posgrado en economía de la Universidad de Wisconsin eran menos propensos a hacer contribuciones a un bien público en un juego experimental. Frank et al. (1993) citan evidencias que sugieren que estudiar economía inhibe la cooperación. El grado en que esas diferencias persisten en distintos estudios experimentales y la causa subyacente de las diferencias que persisten siguen siendo controvertidos. ¿Estudiar economía hace que las personas toleren más el comportamiento egoísta en sí mismas y en las demás? ¿O quizá la disciplina atrae a las personas más egoístas? Frey y Meier (2005) examinaron las contribuciones voluntarias de estudiantes de la Universidad de Zúrich a fondos sociales y encontraron que cuanto más tarde elegían la economía como campo de estudio menos se inclinaban a contribuir, aun antes de que empezaran a estudiar economía. Sea cual fuere la

${ }^{15}$ Ver Fligstein y Shin (2007), Jung y Dobbin (2012), Fourcade y Khurana (2013) y Heilbron et al. (2014).

${ }^{16}$ La muestra incluía 150 de los artículos más citados anteriores a 2008, descargados de SSRN usando el término de búsqueda "remuneración de los ejecutivos" (excluidos los artículos de la encuesta). 
dinámica subyacente, hay evidencia sugestiva y convergente de que los economistas son más francos acerca de la búsqueda de su propio interés, o simplemente más egoístas (por disposición o como resultado de la formación).

La posición de los economistas tiende a ser minoritaria en lo que respecta a algunas de sus ideas más queridas. Sapienza y Zingales (2013) argumentan que cuanto más concuerdan entre sí los economistas estadounidenses, más se distancian del ciudadano promedio. En general, por supuesto, prefieren las soluciones de mercado para enfrentar problemas sociales (Whaples, 2009). Apoyan el pago a los donantes de órganos, pero para el público esa idea es de mal gusto. Una gran mayoría de economistas cree que la protección comercial es económicamente perjudicial, pero cuando se pregunta si "comprar americano" es bueno para la economía, el estadounidense promedio está de acuerdo (Sapienza y Zingales, 2013, 638). Los economistas creen que un mecanismo de mercado como el impuesto a la emisión de carbono o un sistema de límites y negociación de bonos de contaminación es menos costoso y más eficaz para frenar el cambio climático que medidas regulatorias como las normas sobre emisión de vehículos, pero la mayoría de sus conciudadanos discrepa. Los economistas pueden asesorar a los gobiernos pero no suelen convencer a la gente.

Los economistas académicos votan más a la izquierda que los ciudadanos estadounidenses, igual que sus pares universitarios, desde que se hacen encuestas de opinión política en ese entorno. Ladd y Lipset (1976) presentan una encuesta clásica. Aunque, en promedio, el contingente de libertarios entre los economistas es mucho mayor que entre los votantes, como grupo los economistas aún dicen que confían más en el gobierno, con variaciones institucionales importantes. Según la encuesta de Gross y Simmons al profesorado estadounidense (ver Gross, 2013), los economistas están a medio camino entre los profesores de humanidades y otras ciencias sociales -situados a su izquierda-y los de las escuelas de negocios -situados a su derecha- en la mayoría de sus opiniones políticas. Por ejemplo, dos tercios de los sociólogos dicen que las corporaciones obtienen demasiadas ganancias, pero solo un tercio de los economistas y prácticamente ningún profesor de finanzas piensan eso. La gran mayoría de los sociólogos (el 90\%) concuerda en que "el gobierno debe hacer más para ayudar a los necesitados, aunque esto signifique profundizar la deuda", pero apenas la mitad de los economistas y una tercera parte de los profesores de finanzas están de acuerdo con esa afirmación. 
La visión del mundo de los economistas, como la de todas las personas, es en parte producto de sus circunstancias sociales particulares: de la situación material y simbólica y la trayectoria de su grupo y de la de cada miembro del grupo. En relación con otros académicos, a los economistas les va mejor en términos de ingresos. Según el Bureau of Labor Statistics, el salario promedio de los 11.000 profesores de economía en institutos universitarios, universidades y escuelas profesionales era de 103.000 dólares en 2012 y de 160.000 para el 10\% más alto. En comparación, la mediana de los sociólogos era de 76.000 dólares, y de 118.000 para el 10\% más alto. Estas cifras no incluyen fuentes adicionales de ingresos por consultoría y otras actividades, las cuales pueden ser sustanciales (Weyl, de próxima publicación). Además, la situación material de los economistas mejoró notablemente en las últimas dos décadas, sobre todo para los miembros mejor pagados de la profesión, que hoy aventajan ligeramente a los ingenieros mejor remunerados; en cambio, el salario mediano real en muchas profesiones académicas (sobre todo en humanidades) y en Estados Unidos en general apenas aumentó en el mismo periodo, como se ve en la gráfica 5 (que cubre además a los profesores de institutos universitarios comunitarios). Falta saber cómo ha afectado esta experiencia de movilidad social de grupo y de creciente desigualdad entre disciplinas la apreciación de los economistas acerca del deterioro de la situación económica de sus colegas académicos menos afortunados y de los ciudadanos.

Esta creciente distancia social entre los economistas y el público en general sería irrelevante si su misión no fuera maximizar el bienestar de la gente común. La economía como profesión está fuertemente entrelazada a la administración pública, las empresas y las organizaciones internacionales, que no solo proporcionan recursos a los economistas y recogen sus datos, sino que también fomentan una cultura "adecuada" o, como dicen los sociólogos, un habitus particular, una disposición a intervenir en el mundo (Bourdieu y Wacquant, 1992). Los economistas, ante todo los actuales, quieren arreglar las cosas, lo que es un producto de su confianza teórica y de la posición de su disciplina en la sociedad (Mitchell, 1998). Sus modelos invocan rutinariamente el personaje mítico del "planificador social" benevolente, imaginando que esta entidad haría el mundo más rico, más saludable y menos vulnerable a las crisis. Los economistas han elaborado un marco teórico preciso para determinar cuándo los mercados producen eficiencia y cuándo pueden ocurrir fallas del mercado, y disponen de un vasto arsenal econométrico para analizar 
Gráfica 5

Salario mediano anual y salario del percentil 90 en disciplinas seleccionadas 1999-2012

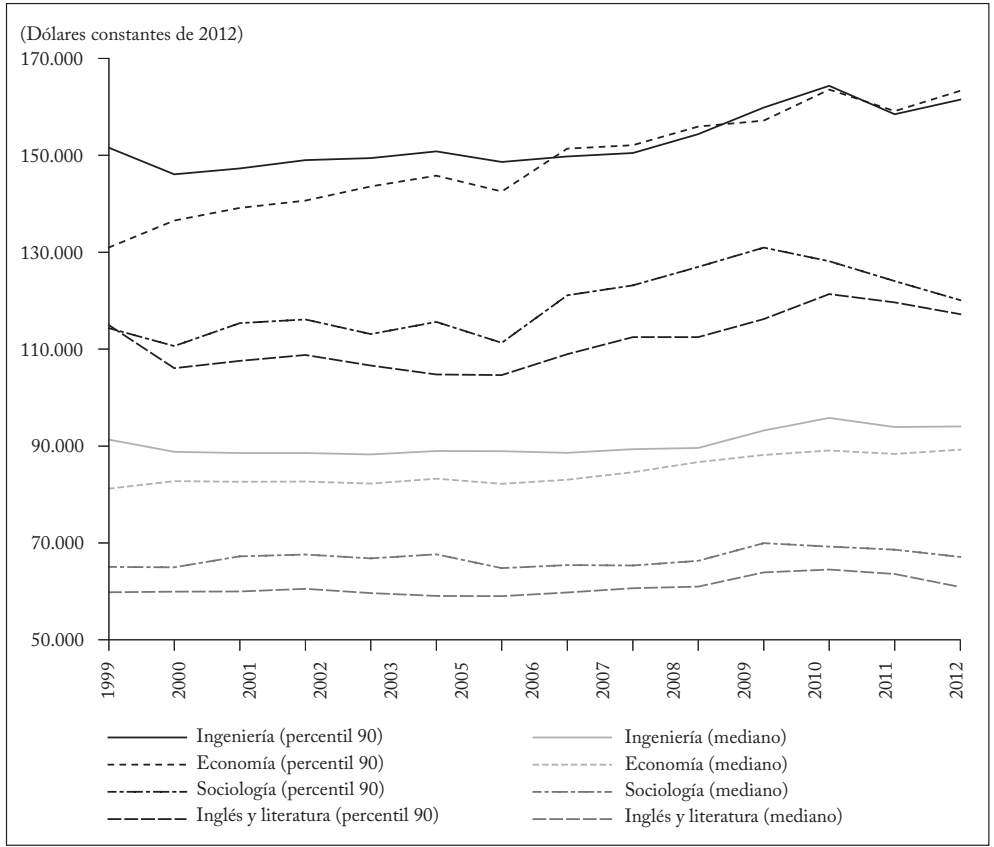

Fuente: Bureau of Labor Statistics, Occupational Employment Statistics, [http://www.bls.gov/oes/tables.htm].

los efectos de las propuestas de política reales. En el último cuarto del siglo XX también empezaron a realizar experimentos estrictamente especificados, poniendo cada vez más la administración de la política social o la ayuda al desarrollo al servicio de la investigación (p. ej., Banerjee y Duflo, 2013). (Cabe señalar de paso que los experimentos de los economistas son muy diferentes de los de los sociólogos, que tienden a hacer experimentos para entender cómo vive la gente). Por último, los economistas tienen mucha seguridad en sus criterios de juicio últimos: su predilección por la eficiencia sobre la equidad, la revelación de preferencias de comportamiento y el diseño de experimentos en torno a un estrecho menú de opciones. Estos criterios ratifican la orientación hacia la adjudicación política y la asesoría, y la disposición o el afán de servir e intervenir. Si las cosas no funcionan como deberían, puede ser necesario un reajuste o un "empujón" inteligente (Thaler y Sunstein, 2008).

La comparación con los sociólogos es aquí de nuevo diciente: los sociólogos también pueden competir por ser consejeros del príncipe, pero han tenido mucho menos éxito para lograr influencia. Ante todo 
porque la economía y la sociología tienen orientaciones diferentes hacia el tiempo. Los economistas suelen prestar poca atención a la historia, "viven en el ahora", y "ven las trayectorias del presente hacia adelante"; los sociólogos tienen la actitud contraria, ven el presente como resultado de un conjunto de procesos anteriores (Abbott, 2005). Por ello, a menudo se sienten marginados $y$ rehúyen la participación política directa. Sus hábitos intelectuales se centran en la crítica social, debido precisamente a que ya están afuera: en palabras de Pierre Bourdieu, "hacen de la necesidad virtud". La auto percepción refleja bien estas diferencias. En la encuesta de Gross y Simmons al profesorado estadounidense, los economistas se describieron a sí mismos como "intelectuales" “ "científicos". Los sociólogos se sintieron más cómodos con los términos "críticos sociales" y "científicos", abrazando inconscientemente su posición periférica sin abandonar la manta de la ciencia. La combinación de su deseo de relevancia y su profunda ambivalencia hacia el poder genera disposiciones muy diferentes: los sociólogos analizan críticamente, a veces en forma incitante y provocadora, pero rara vez se aventuran a proponer soluciones y remedios (no están en condiciones de proponerlos y tal vez serían reacios si tuviesen la oportunidad). Los politólogos, curiosamente, se veían ante todo como "intelectuales", pero, quizás como reflejo de su mayor proximidad al juego político, también eran más propensos a distanciarse del término "científicos" que los sociólogos o los economistas.

El resultado de la confianza de los economistas en sus intervenciones en el mundo es que la economía, a diferencia de la sociología o la ciencia política, se ha convertido en una poderosa fuerza transformadora. Los economistas no simplemente describen una realidad externa, también hacen que suceda difundiendo sus consejos y herramientas; en términos sociológicos, “actúan” la realidad (Callon, 1998). Los elementos y técnicas de las teorías económicas se incrustan en los procesos económicos de la vida real, y pasan a formar parte del equipo que los actores económicos y los ciudadanos comunes utilizan en su interacción económica cotidiana. En algunos casos, el uso práctico de esas técnicas puede alinear el comportamiento real de la gente con su descripción en los modelos económicos. Al cambiar la naturaleza de los procesos económicos desde dentro, la economía tiene el poder para hacer más verdaderas sus teorías. Por ejemplo, MacKenzie (2006) muestra que las teorías financieras académicas dieron lugar a enormes mercados de futuros, opciones y otros derivados financieros: el uso de la fórmula Black-Scholes-Merton por los actores del mercado 
provocó alteraciones que mejoraron el ajuste del modelo a la realidad del precio de las opciones.

E1 mundo ha cambiado mucho bajo la influencia de los economistas. El razonamiento, la pericia y las técnicas económicas impregnan las actividades, la cultura (incluidos medios de comunicación y bestsellers) y las instituciones capitalistas, desde los hospitales hasta los tribunales y las universidades (Hirschman y Berman, 2014). Los economistas dispensan su pericia en casi todos los asuntos de política pública y hacen avances continuos en los negocios y el gobierno, a menudo en altos cargos políticos (Montecinos y Markoff, 2009). Ministerios de finanzas, bancos centrales, organismos gubernamentales, organizaciones internacionales y las firmas de consultoría dominantes albergan grandes grupos de economistas profesionales, que pretenden un poder tutelar sobre "la economía" al tiempo que ven que las sociedades participan en un proceso sin fin, pero en últimas beneficioso, de reconstrucción económica. Por último, el lenguaje racional formalista de la profesión apuntala sus aspiraciones universalistas. Las modas económicas traspasan fronteras y atraen gentes y técnicas a su paso. Mucho más que la sociología o la ciencia política, la economía es una disciplina simbólica y materialmente globalizada (Fourcade, 2006).

La mayoría de los economistas se siente entonces muy segura de su valor agregado. Se regocija en este sentimiento debido al marco bastante unificado de su disciplina, los altos salarios que muchos de ellos creen que reflejan un valor fundamental y toda una estructura institucional-desde periódicos hasta comités del Congreso y círculos políticos internacionales- que recurre a ellos en busca de respuestas, sobre todo en tiempos difíciles. De hecho, la reciente crisis económica y financiera hizo más y no menos visible a la disciplina en su conjunto, y más solicitada su pericia: las recesiones de comienzos de los ochenta y la Gran Depresión de los años treinta tuvieron el mismo efecto.

Pero debido a que la economía es una fuerza transformadora y a que sus operarios tienden a estar a cargo, los economistas también están más expuestos. La vorágine financiera de 2008, que pocos miembros de la profesión previeron (pero cuyo origen institucional se remonta, en parte, a las medidas por las que algunos de ellos cabildearon), llevó a que muchos economistas hicieran un examen de conciencia sobre su falta de conciencia, su optimismo intelectual y la confiabilidad de su pretendida pericia. Después de las incómodas entrevistas en el documental Inside Job, en el que reputados 
miembros de la profesión negaron enfáticamente posibles conflictos de interés, la American Economic Association promovió una serie de directrices éticas. Desde su poderosa tribuna en el New York Times, el ganador del premio Nobel Paul Krugman ventiló en 2009 los trapos sucios de la macroeconomía -usualmente envueltos en modelos esotéricos- en forma pública y feroz. Y los economistas empezaron a hablar de temas distributivos, el pan y la mantequilla de esa otra ciencia social, la sociología, de un modo inimaginable dos o tres décadas antes. Sin duda, los cambiantes hechos de la desigualdad justifican este renovado interés (Piketty, 2014). Pero los vientos intelectuales en la economía también pueden estar cambiando.

\section{CONCLUSIÓN: ¿PERSONAS HUMILDES Y COMPETENTES?}

Es famosa la frase de Keynes: “ ¡Sería maravilloso que los economistas lograran que se piense en ellos como personas humildes y competentes como los dentistas!" $(1962,373)$. La mayoría de los economistas hoy tienen una fuerte inclinación práctica. Creen en el ideal de una democracia asesorada por expertos, en la que su competencia se utilizaría y se desplegaría en cargos no electivos de alto perfil, en el gobierno y en otras instituciones. Pero las sociedades democráticas sospechan profundamente de la pericia (no democrática); y la asesoría económica, a diferencia de la dentistería, nunca puede ser humilde. El hecho es que -en cierto modo, fiel a sus orígenes filosóficos- la economía es una ciencia moral después de todo. A diferencia de los átomos y las moléculas, los “objetos" sobre los cuales intentan actuar los economistas también tienen una visión del mundo. La vida humana es confusa, nunca se entenderá en toda su complejidad ni se moldeará conforme a un plan: las personas actúan de manera imprevista, la política tiene sus propias exigencias, las culturas (que los economistas no entienden bien) oponen resistencia. Así, el éxito de los economistas en establecer su dominio profesional también los lanza, en forma inevitable, a las turbulencias de la política democrática y a una intimidad peligrosa con el poder económico, político y administrativo. Se necesita mucha confianza en uno mismo para hacer declaraciones expertas concluyentes en ese contexto. Esa confianza es quizá el mayor logro de la profesión económica; también es su característica más vulnerable, su talón de Aquiles. 


\section{REFERENCIAS BIBLIOGRÁFICAS}

1. Abbott, A. Chaos of disciplines, Chicago, University of Chicago Press, 2001.

2. Abbott, A. 2005. "The idea of outcome in U.S. sociology", G. Steinmetz, ed., The politics of methods in the human sciences: Positivism and its epistemological others, Durham, NC, Duke University Press, pp. 393-426.

3. Angrist, J. D. y J.-S. Pischke. "The credibility revolution in empirical economics: How better research design is taking the con out of econometrics", Journal of Economic Perspectives 24, 2, 2010, pp. 3-30.

4. Banerjee, A. V. y E. Duflo. Poor economics: A radical rethinking of the way to fight global poverty, Gurgaon, Random House, 2013.

5. Baron, J. N. y M. T. Hannan. "The impact of economics on contemporary sociology", Journal of Economic Literature 32, 3, 1994, pp. 1111-1146.

6. Blau, F. D. "Report of the Committee on the Status of Women in the Economics Profession", American Economic Review 96, 2, 2006, pp. 519-526.

7. Blyth, M. Great transformations: Economic ideas and institutional change in the Twentieth Century, Cambridge, Cambridge University Press, 2002.

8. Bourdieu, P. Distinction: A social critique of the judgment of taste, Cambridge, Harvard University Press, 1984.

9. Bourdieu, P. Homo Academicus, Stanford, Stanford University Press, 1988.

10. Bourdieu, P. y L. J. Wacquant. An invitation to reflexive sociology, Chicago, University of Chicago Press, 1992.

11. Bowles, S. "Endogenous preferences: The cultural consequences of markets and other economic institutions", Journal of Economic Literature 36, 1, 1998, pp. 75-111.

12. Callon, M. "Introduction: The embeddedness of economic markets in economics", The laws of the markets, Oxford, Blackwell, 1998, pp. 1-57.

13. Card, D. y S. DellaVigna. "Nine facts about top journals in economics", Journal of Economic Literature 51, 1, 2013, pp. 144-1461.

14. Clemens, E. S.; W. W. Powell et al. "Careers in print: Books, journals, and scholarly reputations", American Journal of Sociology 101, 2, 1995, pp. 433-494.

15. Colander, D. "The making of an economist redux", Journal of Economic Perspectives 19, 1, 2005, pp. 175-198.

16. Cole, S. “The hierarchy of the sciences?”, American Journal of Sociology 89, 1, 1983, pp. 111-139.

17. Coupe, T. "Revealed performances. Worldwide rankings of economists and economics departments 1969-2000", Universidad Libre de Bruselas, 2004, [http://web.archive.org/web/20070717035652/http:// homepages.ulb.ac.be/ tcoupe/ranking.html].

18. Ellison, G. "How does the market use citation data? The Hirsch Index in economics”, NBER working paper 16419, 2010.

19. Ellison, G. "Is peer review in decline?", Economic Inquiry 49, 3, 2011, pp. 635-657. 
20. Fehr, E. y K. Hoff. "Introduction. Tastes, castes and culture: The influence of society on preferences", Economic Journal 121, 556, 2011, pp. F396-F412.

21. Fligstein, N. y T. Shin. "Shareholder value and the transformation of the U.S. economy, 1984-2000”, Sociological Forum 22, 4, 2007, pp. 399-424.

22. Fourcade, M. "The construction of a global profession: The transnationalization of economics", American Journal of Sociology 112, 1, 2006, pp. 145-194.

23. Fourcade, M. 2009. Economists and societies: Discipline and profession in the United States, Great Britain, and France, 1890s to 1990s, Princeton y Oxford, Princeton University Press.

24. Fourcade, M. y R. Khurana. "From social control to financial economics: The linked ecologies of economics and business in Twentieth Century America", Theory and Society 42, 2, 2013, pp. 121-159.

25. Frank, D. J. y J. Gabler. Reconstructing the University: Worldwide shifts in academia in the 20th Century, Stanford, Stanford University Press, 2006.

26. Frank, R. H.; T. Gilovich y D. T. Regan. "Does studying economics inhibit cooperation?", Journal of Economic Perspectives 7, 2, 1993, pp. 159-171.

27. Freeman, R. B. “It's better being an economist (But don't tell anyone)", Journal of Economic Perspectives 13, 3, 1999, pp. 139-145.

28. Frey, B. S. y S. Meier. "Selfish and indoctrinated economists?”, European Journal of Law and Economics 19, 2, 2005, pp. 165-171.

29. Godechot, O. "How did the neoclassical paradigm conquer a multidisciplinary research institution?", Revue de la régulation 10, 2011, [http://regulation.revues.org/9429].

30. Gross, N. Why are professors liberal and why so conservatives care?, Cambridge, Mass., Harvard University Press, 2013.

31. Gross, N. y S. Simmons. "The social and political views of American professors", working paper, 2007, [http://citeseerx.ist.psu.edu/viewdoc/ download?doi=10.1.1.147.6141\&rep=rep1\&type=pdf ].

32. Hamermesh, D. S. "Six decades of top economics publishing: Who and how?", Journal of Economic Literature 51, 1, 2013, pp. 162-172.

33. Han, S.-K. "Tribal regimes in academia: A comparative analysis of market structure across disciplines”, Social Networks 25, 2003, 3, pp. 251-280.

34. Hansen, W. L. "The education and training of economics doctorates: Major findings of the Executive Secretary of the American Economic Association's Commission on Graduate Education in Economics", Journal of Economic Literature 29, 3, 1991, pp. 1054-1087.

35. Haskell, T. L. The emergence of professional social science: The American Social Science Association and the Nineteenth-Century crisis of authority, Baltimore, Johns Hopkins University Press, 2000.

36. Heilbron, J.; J. Verhael y S. Quak. "The origins and early diffusion of 'shareholder value' in the United States", Theory and Society 43, 1, 2014, pp. 1-22. 
37. Hirshman, D. y E. P. Berman. "Do economists make policies? On the political effects of economics", Socio-Economic Review 12, 4, 2014 , pp. 779-811.

38. Isaac, J. “Theorist at work: Talcott Parsons and the Carnegie Project on Theory, 1949-1951", Journal of the History of Ideas 71, 2, 2010, pp. 287-311.

39. Jacobs, J. A. In defense of disciplines: Interdisciplinarity and specialization in the research university, Chicago y Londres, University of Chicago Press, 2013.

40. Jelveh, Z.; B. Kogut y S. Naidu. "Political language in economics", Columbia Business School research paper 14-57, 2014.

41. Jovanovic, F. "The construction of the canonical history of financial economics", History of Political Economy 40, 2, 2008, pp. 213-242.

42. Jung, J. y F. Dobbin. "Finance and institutional investors", K. K. Cetina y A. Preda, eds., The Oxford handbook of the sociology of finance, Nueva York, Oxford University Press, 2012, pp. 52-74.

43. Kelly, M. A. y S. Bruestle. "Trends of subjects published in economic journals, 1969-2007”, Economic Inquiry 49, 3, 2011, pp. 658-673.

44. Keynes, J. M. Essays in persuasion [1931], Nueva York, W. W. Norton, 1962.

45. Krugman, P. "How did economists get it so wrong?", New York Times Magazine, 2 de septiembre de 2009.

46. Laband, D. N. y M. J. Piette. "Favoritism versus search for good papers: Empirical evidence regarding the behavior of journal editors", Journal of Political Economy 102, 1, 1994, pp. 194-203.

47. Ladd, E. C. y S. M. Lipset. The divided academy: Professors and politics, Nueva York, W. W. Norton, 1976.

48. Lamont, M. How professors think: Inside the curious world of academic judgment, Cambridge y Londres, Harvard University Press, 2009.

49. Lazear, E. P. "Economic imperialism", Quarterly Journal of Economics 115, 1, 2000, pp. 99-146.

50. Leamer, E. “Tantalus on the road to Asymptopia”, Journal of Economic Perspectives 24, 2, 2010, pp. 31-46.

51. Lebaron, F. La croyance économique. Les économistes entre science et politique, París, Seuil, 2000.

52. Lévi-Strauss, C. The elementary structures of kinship [1949], Boston, Mass., Beacon Press, 1969.

53. MacKenzie, D. An engine, not a camera: How financial models shape markets, Cambridge, Mass., MIT Press, 2006.

54. Marwell, G. y R. E. Ames. "Economists free ride, does anyone else? Experiments on the provision of public goods", Journal of Public Economics 15, 3, 1981, pp. 295-310.

55. Medoff, M. H. "Editorial favoritism in economics?", Southern Economic Journal 70, 2, 2003, pp. 425-434.

56. Mirowski, P. More heat than light. Economics as social physics, physics as nature's economics, Nueva York, Cambridge University Press, 1989.

57. Mitchell, T. "Fixing the economy", Cultural Studies 12, 1, 1998, pp. 82-101. 
58. Montecinos, V. y J. Markoff, eds. Economists in the Americas, Cheltenham y Northampton, Edward Elgar, 2009.

59. Nik-K., E. y R. van Horn. "Inland empire: Economics' imperialism as an imperative of Chicago neoliberalism", Journal of Economic Methodology 19, 3, 2012, pp. 259-282.

60. Ollion, E. y A. Abbott. "Quarante ans de sociologie française aux États-Unis. Note sur la réception des sociologues français OutreAtlantique (1960-2009)", D. Demaziere, D. Lorrain y C. Paradeise, eds., Transmissions. Une communauté en héritage, París, PUF, de próxima publicación.

61. Pieters, R. y H. Baumgartner. "Who talks to whom? Intra and interdisciplinary communications of economic journals", Journal of Economic Literature 40, 2, 2002, pp. 483-509.

62. Piketty, T. Capital in the Twenty-First Century, Cambridge, Mass., Harvard University Press, 2014.

63. Prasad, M. The politics of free markets: The rise of neoliberal economic policies in Britain, France, Germany, and the United States, Chicago y Londres, University of Chicago Press, 2006.

64. R Core Team. R: A language and environment for statistical computing, Viena, R Foundation for Statistical Computing, 2014, [http:// www.R-project.org/].

65. Ross, D. The origins of American social science, Nueva York, Cambridge University Press, 1991.

66. Sapienza, P. y L. Zingales. "Economic experts versus average Americans", American Economic Review 103, 3, 2013, pp. 636-642.

67. Sims, C. A. "But economics is not an experimental science", Journal of Economic Perspectives 24, 2, 2010, pp. 59-68.

68. Steinmetz, G., ed. The politics of method in the human sciences: Positivism and its epistemological others, Durham y Londres, Duke University Press, 2005.

69. Stigler, G. y G. Becker. "De gustibus non est disputandum”, American Economic Review 67, 2, 1977, pp. 76-90.

70. Thaler, R. H. y C. R. Sunstein. Nudge. Improving decisions about health, wealth and happiness, Nueva York, Penguin Books, 2008.

71. Weyl, G. "Finance and the common good", Conclusión de Après le déluge: Finance and the common good after the crisis, E. Glaeser, T. Santos y G. Weyl, eds., Chicago y Londres, University of Chicago Press, de próxima publicación.

72. Whaples, R. "The policy views of American Economic Association members: The results of a new survey", Economic Journal Watch 6, 3, 2009, pp. 337-348.

73. Whitley, R. The intellectual and social organization of the sciences, Oxford, Clarendon Press, 1984.

74. Wu, S. "Recent publishing trends at the AER, JPE and OJE", Applied Economics Letters 14, 1, 2007, pp. 59-63.

75. Young, C. "The emergence of sociology from political economy in the United States: 1890 to 1940", Journal of the History of the Behavioral Sciences 45, 2, 2009, pp. 91-116. 
76. Zingales, L. “Preventing economists' capture”, D. Carpenter y D. A. Moss, eds., Preventing regulatory capture: Special interest influence and how to limit it, cap. 6, Nueva York, Cambridge University Press, 2013. 